\title{
Do professional norms in the banking industry favor risk-taking?
}

Cohn, Alain ; Fehr, Ernst ; Maréchal, Michel André

\begin{abstract}
In recent years, the banking industry has witnessed several cases of excessive risk-taking that frequently have been attributed to problematic professional norms. We conduct experiments with employees from several banks in which we manipulate the saliency of their professional identity and subsequently measure their risk aversion in a real stakes investment task. If bank employees are exposed to professional norms that favor risk-taking, they should become more willing to take risks when their professional identity is salient. We find, however, that subjects take significantly less risk, challenging the view that the professional norms generally increase bank employees' willingness to take risks.
\end{abstract}

DOI: https://doi.org/10.1093/rfs/hhx003

Posted at the Zurich Open Repository and Archive, University of Zurich ZORA URL: https://doi.org/10.5167/uzh-131526

Journal Article

Originally published at:

Cohn, Alain; Fehr, Ernst; Maréchal, Michel André (2017). Do professional norms in the banking industry favor risk-taking? Review of Financial Studies, 30(11):3801-3823.

DOI: https://doi.org/10.1093/rfs/hhx003 
University of Zurich

Department of Economics

Working Paper Series

ISSN 1664-7041 (print)

ISSN 1664-705X (online)

Working Paper No. 244

\section{Do Professional Norms in the Banking Industry Favor Risk-taking?}

Alain Cohn, Ernst Fehr and Michel André Maréchal

March 2017 


\title{
Do Professional Norms in the Banking Industry Favor Risk-taking?*
}

\author{
Alain Cohn, Ernst Fehr and Michel André Maréchal
}

\begin{abstract}
In recent years, the banking industry has witnessed several cases of excessive risktaking that frequently have been attributed to problematic professional norms. We conduct experiments with employees from several banks in which we manipulate the saliency of their professional identity and subsequently measure their risk aversion in a real stakes investment task. If bank employees are exposed to professional norms that favor risk-taking, they should become more willing to take risks when their professional identity is salient. We find, however, that subjects take significantly less risk, challenging the view that the professional norms generally increase bank employees' willingness to take risks.
\end{abstract}

JEL classification: G02, M14, C93

Keywords: Risk culture, Banking industry, Experiment.

* Cohn: Booth School of Business, University of Chicago, 5807 S Woodlawn Ave, Chicago, IL 60637, U.S., email: alain.cohn(at)chicagobooth.edu. Fehr and Maréchal: University of Zurich, Department of Economics, Bluemlisalpstrasse 10, CH-8006 Zurich, Switzerland, emails: ernst.fehr(at)econ.uzh.ch and michel.marechal(at)econ.uzh.ch. We thank the participating bank and the alumni network organizations of two education programs for enabling the research, Dominic Bigliel and Milena Brunner for research assistance, Charles Efferson and Sally Gschwend for reading the manuscript, and James Choi, Thomas Epper, Nick Netzer, Paul Smeets, Philip Strahan, and Alexander Wagner, and audiences at the University of Innsbruck, University of Zurich, and the Interdisciplinary Conference on Personal Identity and Decision Making in Chicago for valuable feedback. Financial support from the European Research Council Grant "Foundations of Economic Preferences" and the Gottlieb Duttweiler Institute is gratefully acknowledged. 
Financial risks are inherent in most banks' core business activities, such as investing and lending money to individuals, organizations, and governments. In recent years, however, the extent of risk-taking in the banking industry has been widely questioned. For example, there is an emerging consensus among academics and regulators that excessive risk-taking in the banking industry was a major contributor to the global financial crisis (e.g., Diamond and Rajan 2009; Financial Crisis Inquiry Commission 2011; Freixas and Dewatripont 2012). The issue of excessive risk-taking has led to active discussions among policy makers and regulators about its possible roots. Many believe that the prevailing professional norms - that is, views about acceptable behavior that are widely shared among members of a specific profession - favor excessive risk-taking by making employees less risk averse. Consequently, policy makers and regulators have called for a change in professional norms in an attempt to address the problem of excessive risktaking (e.g., House of Commons Treasury Committee 2008; Power, Ashby, and Palermo 2013; International Monetary Fund 2014). But empirical knowledge about whether the professional norms in the banking industry reduce employees' risk aversion has proven elusive.

Measuring the impact of professional norms on employees' risk preferences is challenging. A simple comparison of risk-taking behavior between bank employees and other professionals may not identify differences in professional norms across industries because professional groups with different occupational norms also vary along many other dimensions, some of which may be unobservable. For example, it is possible that the banking industry attracts individuals with a different propensity to take risks relative to other industries. In addition, bank employees may be, in general, more willing to take risks simply because they are used to making risky financial decisions or because they are less likely to be financially constrained. Such latent differences across occupational groups make isolating professional norms from other determinants of risk-taking behavior extremely 
difficult.

We take a different approach for studying the impact of professional norms on bank employees' risk aversion. Our approach is based on identity theory, which proposes that individuals have multiple social identities or roles, such as their gender, ethnicity, or occupation (e.g., Akerlof and Kranton 2000). According to this theory, identities are tied to norms that prescribe "how one should behave" in a given situation. For example, bank employees may be less risk averse in their role as bank employees than in their private lives, where a different set of norms applies. The extent to which a particular identity and associated norms guide behavior depends on the relative importance or salience of the identity in a person's mind (e.g., Benjamin, Choi, and Strickland 2010). Thus, if the professional norms in the banking industry encourage risk-taking, we should observe that bank employees become more willing to take risks when their professional identity is more salient.

To test this conjecture, we conducted an experiment with 128 employees of a large, international bank. Participants were randomly assigned to either a condition that increased the saliency of their professional identity or a control condition where their professional identity was not made salient. We implemented these two conditions in the context of an online survey by varying a subset of the questions in the survey. The treatment group was asked several questions about their occupational background, whereas the control group answered questions unrelated to their profession.

This method of using embedded survey questions to unobtrusively raise the saliency of a particular identity is called "priming." Priming refers to the activation of mental concepts through subtle situational cues (Bargh and Chartrand 2000). Initially developed by psychologists to study automatic cognitive processes, priming also has become an established method in economics (Benjamin, Choi, and Strickland 2010; Benjamin, Choi, and Fisher 2016; Chen et al. 2014; Cohn, Fehr, and Maréchal 2014; Hoff and Pandey 
2014; Cohn, Maréchal, and Noll 2015; see also Cohn and Maréchal 2016 for a literature review). Here, the key benefit of priming is that it allows us to make a comparison within a specific profession. In this way, we avoid the problems mentioned above related to selection and omitted variable bias. In other words, because of the random assignment of bank employees to different priming conditions, there are no observable or unobservable differences between treatment and control group. Therefore, any behavioral difference in average risk-taking across conditions identifies the marginal impact of professional identity on subjects' risk preferences without the confounding influence of income, wealth, investment experience, occupational preferences, and other background characteristics that may vary across professional groups.

Following the priming manipulation, we measured subjects' willingness to take risks in a simple investment task in which they could earn a significant amount of money (up to an equivalent of US $\$ 500)$. Subjects received an endowment of US $\$ 200$ that they could invest in a risky asset with a positive expected return. They could keep the amount they did not invest. Every dollar invested in the risky asset generated a gross return of 2.5 dollars with a probability of $50 \%$ and a return of zero otherwise. Because this task perfectly controls for subjects' probability beliefs and the expected returns, the share invested in the risky asset provides a measure of subjects' risk aversion. ${ }^{1}$

The results show that bank employees took significantly less risk when their professional identity was made more salient. On average, subjects in the professional identity condition invested more than $20 \%$ less in the risky asset relative to the control group. We further find that the effect tends to be especially pronounced for bank employees who work in a core business unit, such as traders, investment bankers, and wealth managers. Therefore, our findings contradict the conventional thinking that the professional norms

\footnotetext{
${ }^{1}$ Note that this also is true if subjects weigh probabilities nonlinearly as assumed in some theories of risk-taking behavior (e.g., cumulative prospect theory) because nonlinear probability weighing and the curvature of the value function jointly determine risk aversion in these theories.
} 
in the banking industry make the employees in that industry less risk averse (e.g., House of Commons Treasury Committee 2008; Power, Ashby, and Palermo 2013; International Monetary Fund 2014). ${ }^{2}$

We further tested whether the treatment effect is specific to financial services professionals or whether people, in general, become more risk averse when they are prompted to think about their job. We therefore additionally recruited 133 nonbanking employees and exposed them to the same manipulation as the bank employees. In contrast to the bank employees, the nonbanking employees did not become more risk averse when we rendered their professional identity more salient. Nonbanking employees in the professional identity condition invested even slightly more in the risky asset than those from the control condition, though the difference between the two conditions is not statistically significant.

Another important question is whether the professional identity effect is specific to employees of one particular bank or whether the effect is a more general phenomenon of the banking industry. We therefore run another experiment with 142 employees from several other banks. The results from the replication experiment are remarkably similar to those from the main experiment: We find that the average share invested in the risky asset is more than $20 \%$ lower in the professional identity relative to the control condition. The treatment effect is therefore not limited to one specific bank, and this suggests that our results capture a more general and potentially industry wide phenomenon.

This paper makes several contributions to the literature. First, our results are informative for current discussions among policy makers and regulators about the drivers of risk-taking in banks. There seems to be broad agreement that excessive risk-taking,

\footnotetext{
${ }^{2}$ For example, a survey of financial services professionals conducted by PricewaterhouseCoopers and the Economist Intelligence Unit found that "culture and excessive risk-taking" (73\%), together with "mispricing of risk" (73\%) and "rewards systems" (70\%), was in the top three of the most frequently cited factors that created the conditions for the crisis (PricewaterhouseCoopers and Economist Intelligence Unit 2008).
} 
particularly in the banking sector, has contributed to the global financial crisis (e.g., Diamond and Rajan 2009; Financial Crisis Inquiry Commission 2011; Freixas and Dewatripont 2012). In search for the underlying causes of excessive risk-taking, researchers initially focused on the prevailing compensation practices in the banking industry because they are commonly thought to overemphasize (short-term) revenue generation relative to the downside risk (Cole, Kanz, and Klapper 2015). ${ }^{3}$ Several other potential reasons, including poor corporate governance (Freixas and Dewatripont 2012) and low capital requirements (Admati and Hellwig 2013), for excessive risk-taking have been proposed. Our paper complements this literature by investigating whether the occupational norms in the banking industry reduce bank employees' risk aversion.

Although our results challenge the view that the prevailing professional norms increase bank employees' willingness to take risks, it is important to note that our results should not be taken as evidence that risk-taking in banks is unproblematic because other sources of excessive risk-taking may exist. It is also interesting to contrast our finding that the saliency of professional identity increases bank employees' risk aversion with another finding using the same subject pool as in our main experiment. These subjects also participated in a task in which they could increase their earnings by behaving dishonestly (Cohn, Fehr, and Maréchal 2014). The results from this task show that making the bank employees' professional identity more salient induced many of them to cheat. As the willingness to cheat and break rules for the sake of personal benefit could also be a potentially important determinant of excessive risk-taking, the combined results of both studies raise the question whether the problem of excessive risk-taking is associated with

\footnotetext{
${ }^{3}$ However, the role of incentive schemes in excessive risk-taking in the banking industry remains controversial. For example, Fahlenbrach and Stulz (2011) find no evidence that banks with higher shares of CEO compensation in stock options and cash bonuses performed worse during the crisis. Murphy (2012) also finds no evidence to support that executive pay provides incentives for excessive risk-taking, but pointed to potential problems with pay systems for lower-level employees, such as traders, brokers, and loan officers.
} 
problematic ethical norms rather than problematic norms about risk-taking. ${ }^{4}$

Second, our paper also contributes to a recent literature on the role of social identity and group affiliation in financial decision making. Several empirical studies document significant associations between political or religious affiliation and investment behavior. For example, Hong and Kostovetsky (2012) find that mutual fund managers who financially support Democrats hold fewer stocks in socially irresponsible companies relative to supporters of the Republican party or nonsupporters (see also Kaustia and Torstila 2011). ${ }^{5}$ With regard to religion, Kumar, Page, and Spalt (2011) find that people who live in mostly Protestant areas are less likely to hold stocks with lottery features, which is consistent with Protestant views on gambling (see also Kumar 2009; Hilary and Hui 2009; Shu, Sulaeman, and Yeung 2012). ${ }^{6}$ More generally, an increasing number of studies examine the origins and development of individuals' risk preferences (e.g., Becker et al. 2014). Empirical work suggests that risk preferences are partly genetically determined (Cesarini et al. 2009; Barnea, Cronqvist, and Siegel 2010) and partly learned through cultural transmission by parents and peers during childhood and adolescence (Dohmen et al. 2011; Booth and Nolen 2012; Eckel et al. 2012). However, the formation process may not cease with the onset of adulthood, as studies indicate that individuals' risk preferences may also be shaped by significant life events, such as natural disasters (Eckel, El-Gamal, and Wilson 2009; Cameron and Shah 2015), economic conditions (Cohn et al. 2015; Guiso, Sapienza, and Zingales 2015a), and violent conflicts (Voors et al. 2012; Callen et al. 2014). Our paper suggests that individuals' risk preferences are also malleable through the work environment.

Third, our paper is further related to a long-standing, mostly theoretical literature

\footnotetext{
${ }^{4}$ The extent and the implications of ethical failures have been discussed by Dyck, Morse, and Zingales (2013), Guiso, Sapienza, and Zingales (2015b), and Zingales (2015).

${ }^{5}$ In a related study, Morse and Shive (2011) find that investors from more patriotic countries exhibit a stronger home bias in their equity selection.

${ }^{6}$ However, the Protestant effect could not been replicated in an experimental setting (Benjamin, Choi, and Fisher 2016).
} 
that considers culture in organizations as conventions and norms (see Hermalin 2001 for an overview of this literature). One strand of this literature considers organizational culture as a set of conventions that help solve coordination problems within organizations (e.g., Kreps 1990; Weber and Camerer 2003; Van den Steen 2010). Another strand views culture as a shared understanding of appropriate behavior that slowly evolves over time (e.g., Hodgson 1996; Rob and Zemsky 2002; Hermalin 2013). This notion of culture assumes that organizational members internalize the norms and values of their surroundings, which induces them to behave accordingly. Our paper falls into the second category, with the notable distinction that we focus on the norms and customs of a profession rather than just a single firm. Of course, financial institutions are not all the same, and they may adopt different workplace norms (even within one company), but they may nonetheless share similar norms, as they operate in the same industry and thus face similar market conditions, regulatory constraints, and stakeholder expectations (Gordon 1991).

\section{Experimental Design}

We conducted our main experiment in 2012 with 128 employees of a large international bank. $^{7}$ About half of them worked in one of the bank's core business unit, i.e., in private banking and asset management, or trading and investment banking functions. The remaining participants worked in a support unit, such as IT, or risk or human resource management. Overall, participants had considerable experience working in the banking industry with an average of 11.5 years (see Table 1 for descriptive statistics of the sample).

We invited subjects via email to participate in a short online survey. ${ }^{8}$ Subjects were

\footnotetext{
${ }^{7}$ We ran a pilot study with 12 subjects whom we exclude from the analysis. The results remain the same if these subjects are included.

${ }^{8}$ The survey was available in the local language and in English. A majority of the participants choose to complete the survey in the local language.
} 
Table 1. Descriptive statistics and randomization check for the main experiment with employees of a large bank

\begin{tabular}{|c|c|c|c|c|c|c|c|}
\hline \multirow[b]{2}{*}{ Variable } & \multicolumn{2}{|c|}{$\begin{array}{c}\text { Total sample } \\
\qquad \mathrm{N}=128\end{array}$} & \multicolumn{2}{|c|}{$\begin{array}{c}\text { Professional } \\
\text { identity } \\
\mathrm{N}=61\end{array}$} & \multicolumn{2}{|c|}{$\begin{array}{l}\text { Control } \\
\mathrm{N}=67\end{array}$} & \multirow[b]{2}{*}{$p$-value } \\
\hline & Mean & SD & Mean & SD & Mean & SD & \\
\hline Age & 38.875 & $(8.048)$ & 38.492 & $(7.025)$ & 39.224 & $(8.917)$ & .631 \\
\hline Male & 0.609 & $(0.490)$ & 0.623 & $(0.489)$ & 0.597 & $(0.494)$ & .764 \\
\hline University degree & 0.617 & $(0.488)$ & 0.574 & $(0.499)$ & 0.657 & $(0.478)$ & .335 \\
\hline Risk literacy & 2.727 & $(1.148)$ & 2.754 & $(1.150)$ & 2.701 & $(1.155)$ & .809 \\
\hline Foreign nationality & 0.180 & $(0.385)$ & 0.180 & $(0.388)$ & 0.179 & $(0.386)$ & .986 \\
\hline Relative income & 3.945 & $(1.330)$ & 3.836 & $(1.267)$ & 4.045 & $(1.386)$ & .406 \\
\hline Core business unit & 0.484 & $(0.502)$ & 0.525 & $(0.504)$ & 0.448 & $(0.501)$ & .385 \\
\hline Years in industry & 11.489 & $(7.916)$ & 10.926 & $(6.659)$ & 12.001 & $(8.927)$ & .954 \\
\hline
\end{tabular}

The variables "age" and "years in industry" are measured in years; "male", "university degree", "foreign nationality", and "core business unit" (i.e., private banking and asset management or trading and investment banking functions) are dummy variables; "risk literacy" ranges from 0 (low) to 4 (high); and "relative income" measures income relative to the firm average on a scale from 1 (lower than average) to 7 (higher than average). The last column presents $p$-values for the null hypothesis of perfect randomization ( $\chi^{2}$-tests in case of binary variables and rank-sum tests in case of interval variables).

informed that they could earn money, and they were assured that their individual data would be treated confidentially and never be revealed to their employer. The survey began with filler questions about subjective wellbeing (see Online Appendix). The second part contained our key experimental manipulation. The computer randomly assigned the subjects to one of two conditions, either the professional identity or the control condition. The randomization check in Table 1 confirms that the two experimental groups are similar in terms of observable characteristics, such as their socioeconomic status, risk literacy, and professional background. ${ }^{9}$

In the professional identity condition, subjects were asked seven questions about their occupational background, such as "At which bank are you presently employed?" or "What is your function at this bank?"10 The purpose of these questions was to render subjects' professional identity and associated norms more salient. By contrast, those in the control condition answered seven questions unrelated to their profession, such as "How many hours per week on average do you watch television?" These two sets of questions were

\footnotetext{
${ }^{9}$ All $p$-values reported in this paper are based on two-sided tests.

${ }^{10}$ See the Online Appendix for the full set of questions.
} 
the only difference between the two conditions. This identity priming approach is based on Akerlof and Kranton's (2000) notion that people have multiple social identities that are tied to norms prescribing how one should behave. The idea behind this approach is that individuals experience disutility if they deviate from the norms prescribed by their professional identity (e.g., how much risk one should take as a bank employee). This disutility increases with the strength or weight they attach to their professional identity relative to their nonprofessional identities. Identity priming temporarily amplifies the relative importance of bank employees' professional identity in their individual decisions and, therefore, reveals the identity's marginal behavioral impact. We formally sketch how identity concerns and priming can be incorporated in an expected utility framework in the Appendix.

Following the experimental manipulation, subjects could earn a substantial amount of money (up to US \$500) in a simple investment task adapted from Gneezy and Potters (1997). We use this task to elicit subjects' willingness to take risks under controlled conditions and with real monetary consequences. ${ }^{11}$ Subjects were endowed with US $\$ 200$, of which they could invest any share in a risky asset. The risky asset returned a payoff of 2.5 times the invested amount with a $50 \%$ probability; the invested amount was lost otherwise. The remaining amount that was not invested was automatically transferred to a safe account that paid no interest. Thus, higher investments in the risky asset reflect lower risk aversion. Our research budget allowed us to pay every fifth subject only; actual payment was determined at the end of the experiment, and the payment modality was explained before subjects made their choices. ${ }^{12}$ The expected payoff was nevertheless sizable considering that completing the survey only took about fifteen minutes. The

\footnotetext{
${ }^{11} \mathrm{~A}$ similar task has been used to study myopic loss aversion in experimental asset markets (Gneezy, Kapteyn, and Potters 2003).

${ }^{12}$ Payment schemes with random components are commonly used in risk-taking experiments and mounting evidence suggests that they do not bias behavior (Starmer and Sugden 1991; Cubitt, Starmer, and Sugden 1998; Hey and Lee 2005; March et al. 2014).
} 
outcome of the investment task was revealed at the very end of the experiment. One feature of our design is that subjects' choices in the investment task only affected their own payoff, whereas they are often required to make risky choices for others, such as clients and shareholders, in their daily jobs (Pollmann, Potters, and Trautmann 2014). We deliberately opted for a noninteractive task because we preferred not confounding our measure of risk aversion with social preferences. Since the existing evidence suggests that people's own risk preferences largely determine how they take risks on behalf of others, this should not be a major issue (e.g., Daruvala 2007, Andersson et al. 2014, Eriksen, Kvaloy, and Luzuriaga 2014). Furthermore, a large proportion of bank employees receive their compensation not only in base salaries but also in cash bonuses, stock options, and other performance-contingent rewards (e.g., Bell and Van Reenen 2014). To the extent that compensation depends on the amount of risk taken, bank employees share the risks they take for others.

Subjects additionally performed a coin tossing task in which they could earn up to US $\$ 200$. The investment task and the coin tossing task were presented in counterbalanced order, with one of the two tasks randomly selected for payment at the end of the experiment. We use the coin tossing task as a measure of honesty and report the results in a related, but separate paper (Cohn, Fehr, and Maréchal 2014). We find no evidence that the presence of the coin tossing task affected the results from the investment task. The task order has no effect on investment choices ( $p=.727$, rank-sum test), and responses in the two tasks are unrelated (Spearman's rho $=0.017, p=.853$ ).

After completing the two tasks, subjects solved a word-completion task, which provides us with an implicit measure of professional identity salience. Subjects were presented word fragments they had to complete with the first word that came to their mind. For example, they were shown the word fragment "_ _ o c k", which they could complete with the word "stock," a word bank employees frequently encounter in their professional 
lives, or the word "clock," which is not specific to their daily work. We asked them to solve a total of six word fragments, two of which had no bank-related solution at all in order to disguise the purpose of the task. The other three relevant word fragments were "_ _ o k e r" (e.g., broker vs. smoker), " _ o n e y" (e.g., money vs. honey), and "b _ n d" (e.g., bond vs. band).

The survey concluded with a few questions about participants' socioeconomic background and workplace attitudes. We also measured their risk literacy using the adaptive version of the Berlin Numeracy test developed by Cokely et al. (2012). This test consists of two to three questions and assesses people's knowledge of basic probability theory.

\section{Experimental Results}

This section presents the results in four steps. We first establish that our manipulation of professional identity salience was effective. In a second step, we analyze the effect of professional identity salience on risk-taking behavior for the bank employees from the main experiment. We then examine the results from the placebo experiment with nonbanking employees. Finally, we present the results from the replication experiment using a sample of bank employees from several other banks.

\subsection{Manipulation check}

The results from the word-completion task suggest that our manipulation generated the desired change in professional identity salience (Figure 1). The frequency of bank-related words increased from $26 \%$ in the control to $36 \%$ in the professional identity condition, which corresponds to an increase of almost $40 \%$ ( $p=.035$, rank-sum test). Thus, bankrelated concepts were more accessible in subjects' minds in the professional identity relative to the control condition. 
Figure 1. Manipulation check

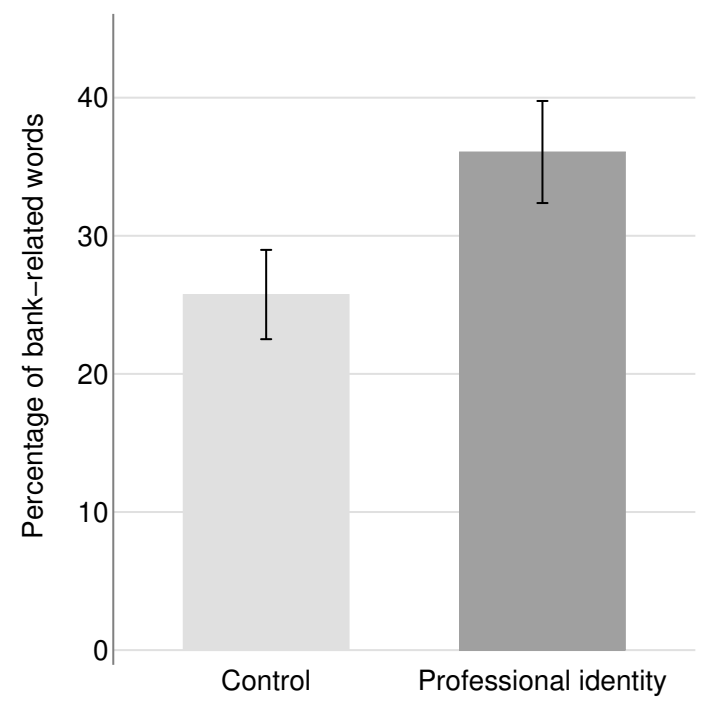

Mean percentage of bank-related words in the wordcompletion task by treatment. Error bars indicate standard error of the mean.

\subsection{Main experiment with employees of a large international bank}

How did the professional identity condition influence bank employees' behavior in the investment task? The left panel in Figure 2 reveals that the average investment share is significantly lower in the professional identity relative to the control condition $(p=.026$, rank-sum test). While subjects in the control condition invested, on average, two-thirds of their endowment in the risky asset (66\%), those in the professional identity condition invested only about half of their endowment (52\%). The right panel of Figure 2 depicts the cumulative distribution functions of investment shares and shows that the professional identity condition led to a general shift of the distribution toward less risky investments.

We also estimate the treatment effect using regression analysis; doing so allows us to control for subjects' background characteristics. Specifically, we estimate the following 
Figure 2. Main experiment with employees of a large international bank
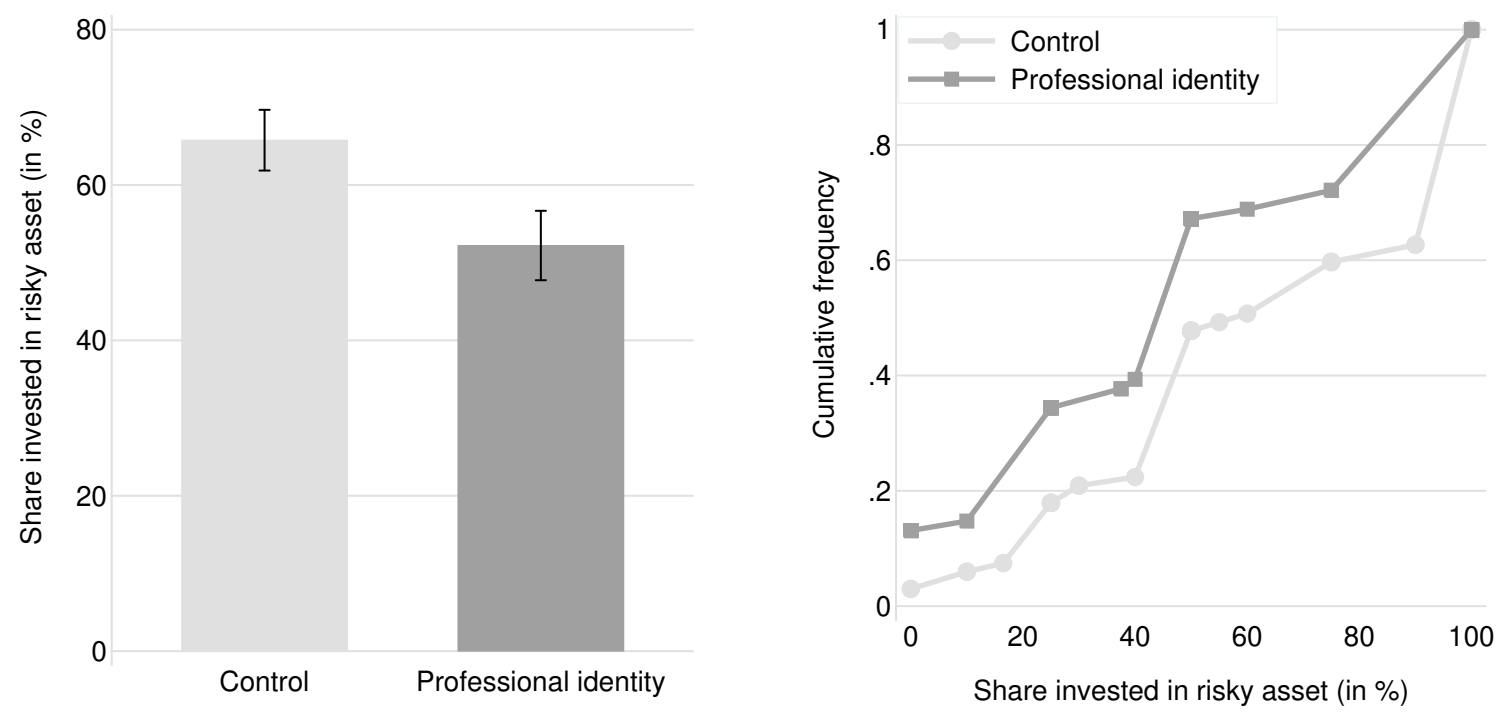

The left panel shows the mean share invested in the risky asset by treatment (in percent of the endowment). Error bars indicate standard error of the mean. The right panel displays the cumulative distribution function of investment shares by condition.

linear regression model using ordinary least squares (OLS):

$$
y_{i}=\beta_{0}+\beta_{1} \operatorname{Prof}_{i}+\gamma X_{i}+\delta Z_{i}+\epsilon_{i}
$$

We regress the share subjects invested in the risky asset $y_{i}$ (in percent of the endowment) on a treatment dummy $\operatorname{Prof}_{i}$ for the professional identity condition, and control for socioeconomic characteristics, $X_{i}$, including subjects' age, gender, education, risk literacy, and nationality. ${ }^{13}$ We also estimate a model in which we additionally control for subjects' professional background, $Z_{i}$, which includes their relative income, business unit, and work experience in the banking industry.

The estimation results are reported in Table 2. Column (1) shows that, controlling for socioeconomic variables, the professional identity condition reduced investments by about 13 percentage points on average $(p=.029, t$-test). We obtain similar results when

\footnotetext{
${ }^{13}$ All our results remain robust if we use a tobit model instead of OLS.
} 
Table 2. Main experiment with employees of a large international bank

\begin{tabular}{lcr} 
Dependent variable & \multicolumn{2}{c}{ Share invested in risky asset (in \%) } \\
\hline Professional identity & $-13.143^{* *}$ & $-13.451^{* *}$ \\
Age & $(5.960)$ & $(6.060)$ \\
& $0.713^{*}$ & 0.892 \\
Male & $(0.386)$ & $(0.550)$ \\
& 4.473 & 4.029 \\
University degree & $(6.414)$ & $(6.732)$ \\
& -0.127 & -0.949 \\
Risk literacy & $(6.087)$ & $(6.591)$ \\
& -0.445 & -0.352 \\
Foreign nationality & $(2.781)$ & $(2.818)$ \\
& 4.727 & 4.153 \\
Relative income & $(7.334)$ & $(7.649)$ \\
& & 1.137 \\
Core business unit & & $(2.605)$ \\
Years in industry & & 3.849 \\
Constant & & $(5.950)$ \\
& & -0.298 \\
Sample size & $35.570^{*}$ & $(0.556)$ \\
$R^{2}$ & $(18.391)$ & 26.444 \\
\hline
\end{tabular}

OLS estimates with robust standard errors in parenthesis. In both columns, the share invested in the risky asset (in percent of the endowment) is regressed on a dummy for the professional identity condition and a set of control variables. The control variables "age" and "years in industry" are measured in years; "male", "university degree", "foreign nationality", and "core business unit" (i.e., private banking and asset management or trading and investment banking functions) are dummy variables; "risk literacy" ranges from 0 (low) to 4 (high); and "relative income" measures income relative to the firm average on a scale from 1 (lower than average) to 7 (higher than average). ${ }^{*},{ }^{* *}$, and ${ }^{* * *}$ indicate significance at the $10 \%$, $5 \%$, and $1 \%$ level, respectively. 
we also control for professional background variables $(p=.028, t$-test $)$, as shown in Column (2). None of the socioeconomic and professional background variables are significantly related to investment choices, with the exception of age in Column (1). Older subjects tended to invest more than younger ones $(p=.067, t$-test). However, this relationship is not significant anymore once we control for subjects' professional background $(p=.107, t$-test $)$.

We additionally explored possible sources of heterogeneity in the treatment effect. For example, we may expect a stronger effect among subjects who deal more directly with risky financial decisions in their daily business. We can analyze the treatment effect separately for subjects from core business units, which includes traders, investment bankers, and wealth managers, and support units, such as IT and risk, and human resource managers. Comparing these two subgroups, we indeed find that the effect tends to be stronger for employees from core business units. They invested about 17 percentage points less in the risky asset when their professional identity was made more salient $(p=$ .042, rank-sum test). By contrast, subjects from support units reduced their investments by less than 11 percentage points, which does not reach statistical significance $(p=.240$, rank-sum test). We find no other significant heterogeneity in the treatment effect based on observable characteristics, including age, gender, income, and banking experience.

Finally, we also examined alternative explanations for why the bank employees took fewer risks when we reminded them of their professional identity. For example, given that the bank employees were working in a professional environment whose reputation has been severely damaged (e.g., Sapienza and Zingales 2012), it is conceivable that they wanted to leave a good impression of the banking profession by acting cautiously. Alternatively, they could have taken fewer risks in order to signal that they are in fact reasonable risk-takers. However, several facts speak against such reputation or image effects. First, the same subjects had no qualms to cheat in order to increase their earnings 
when reminded of their professional identity (Cohn, Fehr, and Maréchal 2014). Second, the amount of money at stake in the investment task was relatively high, meaning that it was potentially expensive for the subjects to give up their preferred choice in order to meet such reputational or image considerations. Third, to directly address the plausibility of the reputation and image mechanism, respectively, we included one question on each motive towards the end of the experiment. Specifically, we asked the subjects "How important is it to you what other people think of you" and "How important is it to you what other people think of the banking industry?," each with answer categories on a 7-point Likert scale from "not at all important" to "very important." Yet, we find no treatment difference in the extent to which bank employees cared about what other people think of them $(p=.170$, rank-sum test) or the banking industry as a whole ( $p=$ .851, rank-sum test), suggesting that the professional identity questions did not alter the participants' image or reputational concerns. Moreover, if image or reputational concerns led to more conservative investment choices, we should observe a negative correlation between investments and the latter survey measures. However, we do not find this to be the case. Subjects who cared more strongly about what people think of them did not invest less in the risky asset (Spearman's rho $=0.028, p=.758$ ), and those subjects who indicated that they care more strongly about the reputation of the banking industry invested even significantly more in the risky asset (Spearman's rho $=0.184, p=.038$ ) . All together, these additional analyses suggest that image or reputation effects do not explain our main results.

\subsection{Placebo experiment with nonbanking employees}

To test whether the professional identity effect is specific to bank employees, we conducted an additional placebo experiment with 133 nonbanking employees recruited from the alumni network of an executive education program. They represented a broad range of 
industries, including pharmaceutical and health care, manufacturing, consulting, telecommunication, and IT. On average, subjects had spent 14.8 years working in the respective industries. $^{14}$

Analogous to the previous experiment, subjects were randomly assigned to either the professional identity or the control condition and then could earn up to US $\$ 500$ in the investment task. Everything essentially was kept the same as in the experiment with the bank employees. However, we dropped a few questions in the last part of the survey (including the risk literacy test) after subjects had already made their investment decisions to shorten the experiment (see Online Appendix). The last column in Table A1 in the Appendix shows that the background characteristics are evenly balanced across conditions, with the exception of university degree $\left(p=.027, X^{2}\right.$-test). We control for this variable in our regression analysis.

Figure 3 presents the results from the placebo experiment with nonbanking employees. The amount of risk taken in the control condition is roughly the same as in the control group of bank employees $(63 \%$ and $66 \%, p=.724$, rank-sum test). However, and in contrast to the previous experiment, the professional identity condition did not reduce risk-taking among nonbanking employees. They invested about $71 \%$ of their endowment in the risky asset when their professional identity was made more salient. Thus, if anything, the professional identity condition tends to increase risk-taking among nonbanking employees, though the difference to the control group is not significant $(p=$ .187, rank-sum test). Furthermore, we find no significant treatment effect in a regression analysis that controls for a comprehensive set of background characteristics, as shown in Column(1) of Table 3 ( $p=.241, t$-tests).

We performed an additional differences-in-differences regression to formally test whether the treatment effect differs between nonbanking employees and bank employees. For this

\footnotetext{
${ }^{14}$ Table $\mathrm{A} 1$ in the Appendix provides sample statistics.
} 
Figure 3. Placebo experiment with nonbanking employees

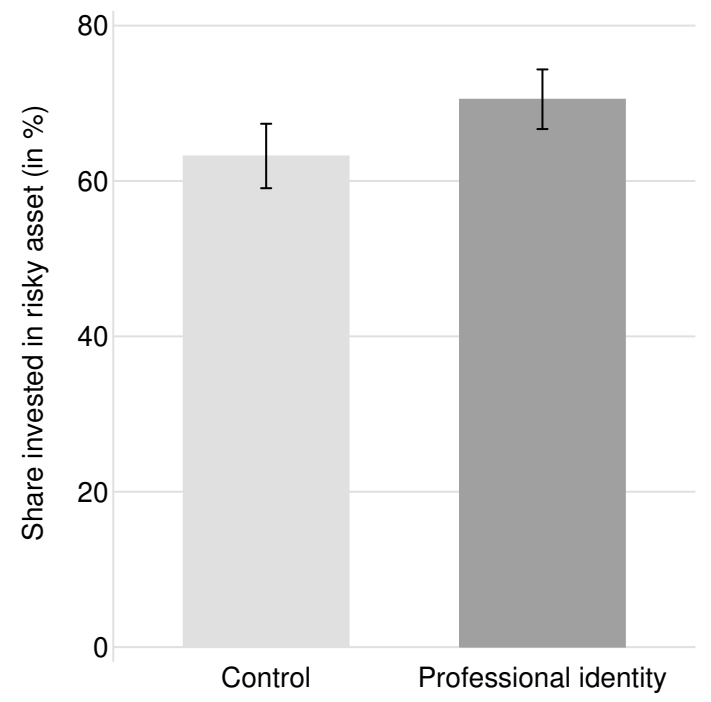

Mean share invested in the risky asset by treatment (in percent of the endowment). Error bars indicate standard error of the mean.

purpose, we pooled the data from the two experiments and estimated the following regression model:

$$
y_{i}=\beta_{0}+\beta_{1} \operatorname{Prof}_{i}+\beta_{2} \operatorname{Main}_{i}+\beta_{3} \operatorname{Prof}_{i} \times \operatorname{Main}_{i}+\gamma X_{i}+\delta Z_{i}+\epsilon_{i} .
$$

Model (2) extends our baseline regression model by adding a dummy variable for observations from the main experiment with bank employees, Main $_{i}$, and the interaction between this dummy and the dummy for the professional identity condition, that is, $\operatorname{Prof}_{i} \times \operatorname{Main}_{i}$. The interaction term allows us to test whether the treatment effect is different for bank employees. We control for socioeconomic and professional background variables $X_{i}$ and $Z_{i}$.

The results of the differences-in-differences regression, shown in Column (2) of Table 3, confirm that the professional identity effect is statistically different for bank and non- 
Table 3. Placebo experiment with nonbanking employees and comparison to main experiment with employees of a large bank

\section{(1)}

Dependent variable

Professional identity

Share invested in risky asset (in \%)

Main experiment

Professional identity $\times$ main experiment

Age

$-0.067$

$(0.459)$

Male

University degree

Foreign nationality

Relative income

$64.654^{* * *}$

(23.688)

$(15.774)$

\begin{tabular}{lrr}
\hline Sample size & 133 & 261 \\
$R^{2}$ & .025 & .051 \\
\hline
\end{tabular}

OLS estimates with robust standard errors in parenthesis. In both columns, the share invested in the risky asset (in percent of the endowment) is regressed on a dummy for the professional identity condition and a set of control variables. Column (1) presents the treatment effect for the nonbanking employees. Column (2) contrasts this effect with the treatment effect for the bank employees from the main experiment. To this end, Column (2) additionally includes a dummy for the bank employees from the main experiment as well as its interaction with the treatment dummy. The control variables "age" and "years in industry" are measured in years; "male", "university degree", and "foreign nationality" are dummy variables. We control for "relative income", even though subjects' income in the placebo experiment was measured relative to the national average on a scale from 1 (lower than average) to 7 (higher than average), whereas it was measured relative to the firm average for the subjects from the main experiment. The results remain the same without controlling for income. ${ }^{*},{ }^{* *}$, and ${ }^{* * *}$ indicate significance at the $10 \%, 5 \%$, and $1 \%$ level, respectively. 
banking employees $(p=.011, t$-test). Thus, while nonbanking employees did not respond to the treatment, bank employees became significantly more risk averse when their professional identity was made more salient.

\subsection{Replication experiment with employees from other banks}

We further examined whether the professional identity effect only applies to one particular bank or whether it generalizes to other banks. To this end, we conducted the experiment with a different sample of bank employees recruited from the alumni network of an advanced banking and finance education program. The sample consists of 142 employees from many different smaller and larger banks. A majority of the subjects (79\%) worked in asset management, private banking, or trading and investment banking (i.e., what we previously referred to as "core business units"). They had, on average, 25 years of work experience in the banking industry, which is more than those from the main experiment. As in the previous two experiments, participants were randomly assigned to either the professional identity or the control condition. They then performed the investment task in which they could earn up to US $\$ 500$. To ensure a high participation rate, we kept the experiment as short as possible and thus dropped the same few items as in the experiment with the nonbanking employees. ${ }^{15}$ Table A1 in the Appendix shows that the individual characteristics are all well balanced across the two conditions.

The results of the replication experiment are remarkably similar to the main experiment. Figure 4 highlights that the average share invested in the risky asset declines from $70 \%$ in the control condition to $54 \%$ in the professional identity condition $(p=.004$, rank-sum test). Thus, both the level of investment as well as the reduction in risk-taking triggered by the professional identity prime closely resembles the pattern of the main experiment.

\footnotetext{
${ }^{15}$ Another difference to the main experiment is that subjects were asked about their beliefs regarding other subjects' behavior in the coin tossing task rather than performing the coin flips themselves.
} 
Figure 4. Replication experiment with employees from other banks

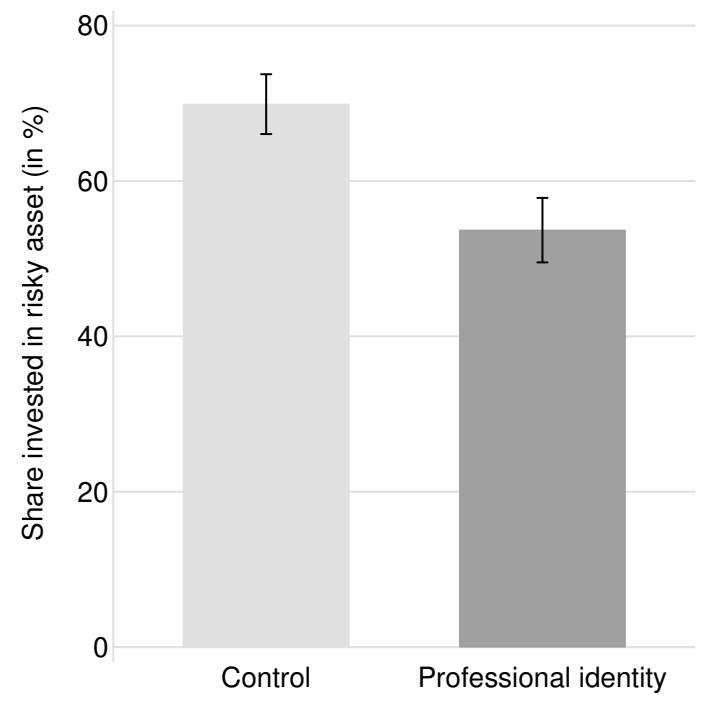

Mean share invested in the risky asset by treatment (in percent of the endowment). Error bars indicate standard error of the mean.

The results of the regression analysis are shown in Table 4. Column (1) presents estimates of the baseline model for subjects from the replication experiment, and Column (2) reports the results from the differences-in-differences comparison with the bank employees from the main experiment. The results from both specifications indicate that subjects in the professional identity condition invested about 15 percentage points less in the risky asset compared to the control group ( $p=.010$ and $p=.008, t$-tests). The effect size is thus even slightly larger in the replication than in the main experiment, possibly due to the fact that the majority of participants in the replication experiment came from a core business unit. However, the interaction term in Column (2) of Table 4 reveals that the effect in the replication experiment does not statistically differ from the main experiment $(p=.876, t$-test). Taken together, the results from the replication experiment support the conclusions from the main experiment. 
Table 4. Replication experiment with employees from other banks and comparison to main experiment with employees of a large bank

\section{(1)}

Dependent variable Share invested in risky asset (in \%)

Professional identity

Main experiment

Professional identity $\times$ main experiment

Age

Male

University degree

Foreign nationality

Relative income

Core business unit

Years in industry

Constant

$-15.062^{* * *}$

$56.098^{*}$

(29.027)

\begin{tabular}{lrr}
\hline Sample size & 142 & 270 \\
$R^{2}$ & .101 & .079 \\
\hline
\end{tabular}

OLS estimates with robust standard errors in parenthesis. In both columns, the share invested in the risky asset (in percent of the endowment) is regressed on a dummy for the professional identity condition and a set of control variables. Column (1) presents the treatment effect for the employees of several banks. Column (2) contrasts this effect with the treatment effect for the bank employees from the main experiment. To this end, Column (2) additionally includes a dummy for the bank employees from the main experiment as well as its interaction with the treatment dummy. The control variables "age" and "years in industry" are measured in years; "male", "foreign nationality", and "university degree" are dummy variables. We control for "relative income" even though subject's income in the replication experiment was measured relative to the national average on a scale from 1 (lower than average) to 7 (higher than average), whereas it was measured relative to the firm average for the subjects from the main experiment. The results remain the same without controlling for income. ${ }^{*},{ }^{* *}$, and ${ }^{* * *}$ indicate significance at the $10 \%, 5 \%$, and $1 \%$ level, respectively. 


\section{Conclusion}

Interest in the professional norms prevailing in the banking industry has grown substantially and continues to preoccupy the leadership at banks and regulatory agencies. We conducted controlled experiments with more than 400 bank employees and other professionals to examine whether an increase in professional identity saliency and associated norms changes bank employees' willingness to take risks. If bank employees are exposed to professional norms that increase their risk appetite, as many people think, they should become more willing to take risks when their professional identity is made salient.

In fact, however, we observe the opposite. Employees from a large international bank took significantly less risk in a real-stake investment task when their professional identity was brought to the forefront of their minds. We replicated this effect in another sample of bank employees from several other banks, but not in a sample of nonbanking employees. Thus, our findings suggest that bank employees share professional norms that make them more risk averse.

A direct implication of our results is that banks can promote risk-averse behavior by using reminders that prime their employees with their professional identity. Similar measures already have proven to be successful in reducing insurance fraud and tax evasion (Shu et al. 2012; Bott et al. 2014). However, the use of reminders requires a detailed analysis of work routines in order to know precisely at which points and times bank employees make critical decisions that entail a potentially large downside risk. This would allow banks to increase the influence of normative demands at the right time and place.

More broadly, our results challenge the view of many financial industry experts and authorities that the professional norms of acceptable risk-taking behavior encourage excessive risk-taking by making bank employees less risk averse. However, this does not imply that we should not be concerned about risk-taking behavior in the banking indus- 
try as other sources of excessive risk-taking may exist. For example, the phenomenon of excessive risk-taking also could be a problem of the prevailing ethical norms and values. Repeated cases of unauthorized trading activities that led to large losses, like the so-called "London Whale" at JPMorgan Chase (U.S. Senate 2013), are perhaps manifestations of professional identities and associated norms that tolerate unethical behavior to a larger degree than in other industries (Cohn, Fehr, and Maréchal 2014). Lacking ethical standards may be equally, if not more, important for banks' exposure to risk compared with the more tangible risks, such as market and credit risks. While banks have sophisticated frameworks for monitoring and managing the core business risks they face in their markets, the management of behavioral risks arising from problematic ethical standards seems to be less developed (Salz and Collins 2013). Thus, expanding the scope of risk management to these behavioral risks may help banks to ensure that their employees make appropriate decisions. 


\section{Appendix}

\section{A Theoretical Framework}

We develop a simple framework based on Benjamin, Choi, and Strickland (2010) to illustrate how professional identity salience can affect risk-taking behavior. We first derive the optimal level of risk-taking in our investment task as a function of individuals' degree of risk aversion. This provides the basis for the actions prescribed by different identities. We then formalize how a temporary increase in the salience of a particular identity changes individuals' willingness to take risk.

Consider an individual who has the opportunity to invest any amount $x$ of an endowment $w$ in a risky asset, and the rest (i.e., $w-x)$ in a riskless asset. The risky asset generates a return of $r$ with a probability of $p$, and a return of -1 otherwise. Consistent with the parametrization of our experimental investment task, we assume that the expected return of the risky asset is strictly positive. The riskless asset has a return of zero. Thus, if the good state of the world occurs, the individual walks away with an income of $c_{1}=(1+r) x+w-x=r x+w$. If the investment is not successful, the individual earns an income of $c_{2}=w-x$. We assume that the individual has a standard concave utility function with constant relative risk aversion (CRRA) of $\gamma>0$, with $\gamma \neq 1$ :

$$
U(c)=\frac{c^{1-\gamma}}{1-\gamma}
$$

Accordingly, the individual chooses to invest $x$ in the risky asset in order to maximize expected utility:

$$
\max _{x \in[0, w]} p \frac{(r x+w)^{1-\gamma}}{1-\gamma}+(1-p) \frac{(w-x)^{1-\gamma}}{1-\gamma}
$$

We define $\tilde{p} \equiv r \frac{p}{1-p}$ as the return-adjusted risk ratio. Then, the first-order condition 
for the optimal amount invested in the risky asset $x^{*}$ is given by

$$
x^{*}=w \frac{\tilde{p}^{\frac{1}{\gamma}}-1}{\tilde{p}^{\frac{1}{\gamma}}+r} .
$$

We are interested in the comparative static properties of the optimal investment $x^{*}$, in particular with regard to how this investment responds to changes in the underlying risk aversion parameter $\gamma$. Calculating the first derivative of Equation (5) with respect to $\gamma$ shows that higher risk aversion, holding all else equal, leads to lower investments in the risky asset:

$$
\frac{d x^{*}}{d \gamma}=-w \frac{(1+r) \tilde{p}^{\frac{1}{\gamma}} \ln \tilde{p}}{\gamma^{2}\left(\tilde{p}^{\frac{1}{\gamma}}+r\right)^{2}}<0 .
$$

Turning to the identity-related part of the model, we assume, for simplicity, that bank employees have two distinct identities, a professional identity and a nonprofessional identity. In our context, each identity prescribes a certain investment, $x_{P}$ and $x_{0}$, based on the optimization problem described above. However, the prescribed choices may be in conflict with each other depending on the degree of risk aversion attached to the particular identities.

To model the internal conflict between the professional and nonprofessional identities and how this conflict affects risk-taking behavior, we assume that bank employees maximize the following utility function:

$$
\max _{x_{i} \in[0, w]} U_{i}=-d\left(s_{i}\right)\left(x_{i}-x_{P}\right)^{2}-\left(1-d\left(s_{i}\right)\right)\left(x_{i}-x_{0}\right)^{2} .
$$

The utility function is a convex combination of the deviations between the actual choice $x_{i}$, and the choices prescribed by the professional identity, $x_{P}$, and the nonprofessional identity, $x_{0}$, respectively. $d\left(s_{i}\right)$ is the decision weight put on the professional identity, with $0 \leq d\left(s_{i}\right) \leq 1, d(0)=0$, and $d^{\prime}>0$. Analogously, $1-d\left(s_{i}\right)$ is the relative 
importance of the nonprofessional identity. The decision weight given to the professional identity, $d\left(s_{i}\right)$, is a function of an individual's current strength of the professional identity, $s_{i}$. The current strength of the professional identity depends on the permanent component $\bar{s}_{i}$, but it can be temporarily altered by situational cues, $\epsilon$, like our experimental manipulation, such that $s_{i}=\epsilon \cdot \bar{s}_{i}$. We assume $0 \leq \epsilon \leq 1$. Thus, $\epsilon=0$ means that the professional identity is not at all salient at the time of making the decision, whereas $\epsilon=1$ implies that the professional identity is fully salient. Solving the maximization problem for individuals with identity concerns yields the following optimal choice:

$$
x_{i}^{*}=d\left(s_{i}\right) x_{P}+\left(1-d\left(s_{i}\right)\right) x_{0} .
$$

Thus, an individual's optimal choice is the weighted average of the prescribed actions of the professional and the nonprofessional identity. Inducing bank employees to think about their professional role (i.e., $\epsilon>0$ ) increases the relative importance of the action prescribed by their professional identity. If, for example, bank employees' professional identity dictates a higher investment than the nonprofessional identity (i.e., $x_{P}>x_{0}$ ) because it is associated with a lower degree of risk aversion (i.e., $\gamma_{P}<\gamma_{0}$ ), then behavior shifts toward more risk-taking. 


\section{B Additional Tables}

Table A1. Descriptive statistics and randomization check for the placebo experiment with nonbanking employees

\begin{tabular}{|c|c|c|c|c|c|c|c|}
\hline \multirow[b]{2}{*}{ Variable } & \multicolumn{2}{|c|}{$\begin{array}{l}\text { Total sample } \\
\qquad \mathrm{N}=133\end{array}$} & \multicolumn{2}{|c|}{$\begin{array}{c}\text { Professional } \\
\text { identity } \\
N=67\end{array}$} & \multicolumn{2}{|c|}{$\begin{array}{l}\text { Control } \\
\qquad \mathrm{N}=66\end{array}$} & \multirow[b]{2}{*}{$p$-value } \\
\hline & Mean & SD & Mean & SD & Mean & SD & \\
\hline Age & 45.526 & $(8.112)$ & 45.075 & $(8.351)$ & 45.985 & $(7.898)$ & 0.607 \\
\hline Male & 0.880 & $(0.327)$ & 0.910 & $(0.288)$ & 0.848 & $(0.361)$ & 0.272 \\
\hline University degree & 0.767 & $(0.424)$ & 0.687 & $(0.467)$ & 0.848 & $(0.361)$ & 0.027 \\
\hline Foreign nationality & 0.075 & $(0.265)$ & 0.075 & $(0.265)$ & 0.076 & $(0.267)$ & 0.980 \\
\hline Relative income & 5.436 & $(1.150)$ & 5.358 & $(1.069)$ & 5.515 & $(1.231)$ & 0.182 \\
\hline Middle management & 0.263 & $(0.442)$ & 0.269 & $(0.447)$ & 0.258 & $(0.441)$ & 0.885 \\
\hline Upper management & 0.639 & $(0.482)$ & 0.612 & $(0.491)$ & 0.667 & $(0.475)$ & 0.511 \\
\hline Years in industry & 14.789 & $(9.067)$ & 15.515 & $(9.114)$ & 14.053 & $(9.029)$ & 0.320 \\
\hline
\end{tabular}

The variables "age" and "years in industry" are measured in years; "male", "university degree", "foreign nationality", "middle management", and "upper management" are dummy variables; "relative income" measures income relative to the national average on a scale from 1 (lower than average) to 7 (higher than average). The last column presents $p$-values for the null hypothesis of perfect randomization ( $\chi^{2}$ tests in case of binary variables and rank-sum tests in case of interval variables). 
Table A2. Descriptive statistics and randomization check for the replication experiment with employees from other banks

\begin{tabular}{|c|c|c|c|c|c|c|c|}
\hline \multirow[b]{2}{*}{ Variable } & \multicolumn{2}{|c|}{$\begin{array}{c}\text { Total sample } \\
\qquad \mathrm{N}=142\end{array}$} & \multicolumn{2}{|c|}{$\begin{array}{c}\text { Professional } \\
\text { identity } \\
\mathrm{N}=72\end{array}$} & \multicolumn{2}{|c|}{$\begin{array}{l}\text { Control } \\
\mathrm{N}=70\end{array}$} & \multirow[b]{2}{*}{$p$-value } \\
\hline & Mean & SD & Mean & $\mathrm{SD}$ & Mean & SD & \\
\hline Age & 47.634 & $(7.416)$ & 47.153 & $(7.466)$ & 48.129 & $(7.386)$ & 0.381 \\
\hline Male & 0.915 & $(0.279)$ & 0.889 & $(0.316)$ & 0.943 & $(0.234)$ & 0.248 \\
\hline University degree & 0.303 & $(0.461)$ & 0.292 & $(0.458)$ & 0.314 & $(0.468)$ & 0.769 \\
\hline Foreign nationality & 0.049 & $(0.217)$ & 0.069 & $(0.256)$ & 0.029 & $(0.168)$ & 0.261 \\
\hline Relative income & 5.662 & $(0.996)$ & 5.694 & (1.030) & 5.629 & $(0.966)$ & 0.601 \\
\hline Core business unit & 0.789 & $(0.410)$ & 0.778 & $(0.419)$ & 0.800 & $(0.403)$ & 0.746 \\
\hline Years in industry & 24.973 & $(8.754)$ & 24.571 & $(8.446)$ & 25.386 & $(9.102)$ & 0.665 \\
\hline
\end{tabular}

The variables "age" and "years in industry" are measured in years; "male", "university degree", "foreign nationality", and "core business unit" (i.e., private banking and asset management or trading and investment banking functions) are dummy variables; "relative income" measures income relative to the national average on a scale from 1 (lower than average) to 7 (higher than average). The last column presents $p$-values for the null hypothesis of perfect randomization $\left(\chi^{2}\right.$ tests in case of binary variables and rank-sum tests in case of interval variables). 


\section{References}

Admati, A. R., and M. F. Hellwig. 2013. The bankers' new clothes: What's wrong with banking and what to do about it. New Jersey: Princeton University Press.

Akerlof, G. A., and R. E. Kranton. 2000. Economics and identity. Quarterly Journal of Economics 115:715-53.

Andersson, O., H. J Holm, J.-R. Tyran, and E. Wengström. 2014. Deciding for others reduces loss aversion. Management Science 62:29-36.

Bargh, J. A., and T. L. Chartrand. 2000. The mind in the middle: A practical guide to priming and automaticity research. In Handbook of research methods in social psychology, eds. H. T. Reis, and C. M. Judd, 253-85. New York: Cambridge University Press.

Barnea, A., H. Cronqvist, and S. Siegel. 2010. Nature or nurture: What determines investor behavior? Journal of Financial Economics 98:583-604.

Becker, A., T. Dohmnen, B. Enke, and A. Falk. 2014. The ancient origins of the crosscountry heterogeneity in risk preferences. Working Paper, University of Bonn.

Bell, B., and J. Van Reenen. 2014. Bankers and their bonuses. Economic Journal 124:F1F21.

Benjamin, D. J., J. J. Choi, and G. W. Fisher. 2016. Religious identity and economic behavior. Review of Economics and Statistics 98:617-37.

Benjamin, D. J., J. J. Choi, and J. A. Strickland. 2010. Social identity and preferences. American Economic Review 100:1913-28.

Booth, A. L., and P. Nolen. 2012. Gender differences in risk behaviour: Does nurture matter? Economic Journal 122:F56-F78.

Bott, K., A. W. Cappelen, E. Ø. Sørensen, and B. Tungodden. 2014. You've got mail: A randomised field experiment on tax evasion. Working Paper, Norwegian School of Economics.

Callen, M., M. Isaqzadeh, J. D. Long, and C. Sprenger. 2014. Violence and risk preference: Experimental evidence from Afghanistan. American Economic Review 104:123-48.

Cameron, L., and M. Shah. 2015. Risk-taking behavior in the wake of natural disasters. Journal of Human Resources 50:484-515.

Cesarini, D., C. T. Dawes, M. Johannesson, P. Lichtenstein, and B. Wallace. 2009. Genetic variation in preferences for giving and risk taking. Quarterly Journal of Economics 124:809-42. 
Chen, Y., S. X. Li, T. X. Liu, and M. Shih. 2014. Which hat to wear? Impact of natural identities on coordination and cooperation. Games and Economic Behavior 84:58-86.

Cohn, A., J. Engelmann, E. Fehr, and M. A. Maréchal. 2015. Evidence for countercyclical risk aversion: an experiment with financial professionals. American Economic Review 105:860-85.

Cohn, A., E. Fehr, and M. A. Maréchal. 2014. Business culture and dishonesty in the banking industry. Nature 516:86-89.

Cohn, A., and M. André Maréchal. 2016. Priming in economics. Current Opinion in Psychology 12:17-21.

Cohn, A., M. A. Maréchal, and T. Noll. 2015. Bad boys: How criminal identity salience affects rule violation. Review of Economic Studies 82:1289-308.

Cokely, E. T, M. Galesic, E. Schulz, S. Ghazal, and R. Garcia-Retamero. 2012. Measuring risk literacy: The Berlin numeracy test. Judgment and Decision Making 7:25-47.

Cole, S., M. Kanz, and L. Klapper. 2015. Incentivizing calculated risk-taking: Evidence from an experiment with commercial bank loan officers. Journal of Finance 70:537-75.

Cubitt, R. P., C. Starmer, and R. Sugden. 1998. On the validity of the random lottery incentive system. Experimental Economics 1:115-31.

Daruvala, D. 2007. Gender, risk and stereotypes. Journal of Risk and Uncertainty 35:26583.

Diamond, D. W., and R. G. Rajan. 2009. The credit crisis: Conjectures about causes and remedies. American Economic Review 99:606-10.

Dohmen, T., A. Falk, D. Huffman, U. Sunde, J. Schupp, and G. G. Wagner. 2011. Individual risk attitudes: Measurement, determinants, and behavioral consequences. Journal of the European Economic Association 9:522-50.

Dyck, A. I. J., A. Morse, and L. Zingales. 2013. How pervasive is corporate fraud? Working Paper, Rotman School of Management.

Eckel, C. C., M. A. El-Gamal, and R. K. Wilson. 2009. Risk loving after the storm: A Bayesian-Network study of Hurricane Katrina evacuees, Journal of Economic Behavior \& Organization 69:110-24.

Eckel, C. C., P. J. Grossman, C. A. Johnson, A. C. M. de Oliveira, C. Rojas, and R. K. Wilson. 2012. School environment and risk preferences: Experimental evidence. Journal of Risk and Uncertainty 45:265-92.

Eriksen, K., O. Kvaloy, and M. Luzuriaga. 2014. Risk-taking with other people's money. Working Paper. 
Fahlenbrach, R., and R. M. Stulz. 2011. Bank CEO incentives and the credit crisis. Journal of Financial Economics 99:11-26.

Financial Crisis Inquiry Commission. 2011. The financial crisis inquiry report. Washington, DC.

Freixas, X., and M. Dewatripont. 2012. The crisis aftermath: New regulatory paradigms. London: Centre for Economic Policy Research.

Gneezy, U., A. Kapteyn, and J. Potters. 2003. Evaluation periods and asset prices in a market experiment. Journal of Finance 58:821-38.

Gneezy, U., and J. Potters. 1997. An experiment on risk taking and evaluation periods. Quarterly Journal of Economics 112:631-45.

Gordon, G. G. 1991. Industry determinants of organizational culture. Academy of Management Review 16:396-415.

Guiso, L., P. Sapienza, and L. Zingales. 2015a. Time varying risk aversion. Working Paper, NBER. 76.

Hermalin, B. E. 2001. Economics and corporate culture. In The international handbook of organizational culture and climate. Chichester, England: John Wiley \& Sons, Ltd.

Hermalin, B. E. 2013. Leadership and corporate culture. In Handbook of organizational economics, eds. R. Gibbons, and J. Roberts, 432-78, New Jersey: Princeton University Press.

Hey, J. D., and J. Lee. 2005. Do subjects separate (or are they sophisticated)? Experimental Economics 8:233-65.

Hilary, G., and K. W. Hui. 2009. Does religion matter in corporate decision making in America? Journal of Financial Economics 93:455-73.

Hodgson, G. M. 1996. Corporate culture and the nature of the firm. In Transaction cost economics and beyond - recent economic thought series, eds. W. Darity, Jr., and J. K. Galbraith, 249-69. New York: Springer.

Hoff, K., and P. Pandey. 2014. Making up people - The effect of identity on performance in a modernizing society. Journal of Development Economics 106:118-31.

Hong, H., and L. Kostovetsky. 2012. Red and blue investing: Values and finance. Journal of Financial Economics 103:1-19. 
House of Commons Treasury Committee. 2008. Banking crisis: dealing with the failure of the UK banks. Seventh Report of Session, Vol. 9.

International Monetary Fund. 2014. Global financial stability report-Risk Taking, liquidity, and shadow banking: Curbing excess while promoting growth. Washington, DC: IMF Publications Services.

Kaustia, M., and S. Torstila. 2011. Stock market aversion? Political Preferences and stock market participation. Journal of Financial Economics 100:98-112.

Kreps, D. M. 1990. Corporate culture and economic theory. In Perspectives on positive political economy, eds. J. E. Alt and K. Shepsle, 90-143, Cambridge: Cambridge University Press.

Kumar, A. 2009. Who gambles in the stock market? Journal of Finance 64:1889-933.

Kumar, A., J. K. Page, and O. G. Spalt. 2011. Religious beliefs, gambling attitudes, and financial market outcomes. Journal of Financial Economics 102:671-708.

March, C., A. Ziegelmeyer, B. Greiner, and R. Cyranek. 2014. Monetary incentives in large-scale experiments: A case study of risk aversion. Working Paper, TUM School of Management.

Morse, A., and S. Shive. 2011. Patriotism in your portfolio. Journal of Financial Markets 14:411-40.

Murphy, K. J. 2012. Pay, politics, and the financial crisis. In Rethinking the financial crisis, eds. A. L. A. Blinder and R. Solow. New York: Russell Sage Foundation.

Pollmann, M. M. H., J. Potters, and S. T. Trautmann. 2014. Risk taking by agents: The role of ex-ante and ex-post accountability. Economics Letters 123:387-90.

Power, M., S. Ashby, and T. Palermo. 2013. Risk culture in financial organisations: A research report. Working Paper, Centre for Analysis of Risk and Regulation, London School of Economics.

PricewaterhouseCoopers and Economist Intelligence Unit. 2008. Reward: A new paradigm?

Rob, R., and P. Zemsky. 2002. Social capital, corporate culture, and incentive intensity. RAND Journal of Economics 33:243-57.

Salz, A., and R. Collins. 2013. Salz review: An independent review of Barclays' business practices. Barclays PLC.

Sapienza, P., and L. Zingales. 2012. A trust crisis. International Review of Finance $12: 123-31$. 
U.S. Senate. 2013. JPMorgan chase whale trades: a case history of derivatives risks and abuses. Permanent Subcommittee on Investigations, Committee on Homeland Security and Governmental Affairs, March, vol. 15.

Shu, L. L., N. Mazar, F. Gino, D. Ariely, and M. H. Bazerman. 2012. Signing at the beginning makes ethics salient and decreases dishonest self-reports in comparison to signing at the end. Proceedings of the National Academy of Sciences 109:15197-200.

Shu, T., J. Sulaeman, and P. E. Yeung. 2012. Local religious beliefs and mutual fund risk-taking behaviors. Management Science 58:1779-96.

Starmer, C., and R. Sugden. 1991. Does the random-lottery incentive system elicit true preferences? An experimental investigation. American Economic Review 81:971-78.

Van den Steen, E. 2010. Culture clash: The costs and benefits of homogeneity. Management Science 56:1718-38.

Voors, M. J., E. E. M. Nillesen, P. Verwimp, E. H. Bulte, R. Lensink, and D. P. Van Soest. 2012. Violent conflict and behavior: a field experiment in Burundi. American Economic Review 102:941-64.

Weber, R. A., and C. F. Camerer. 2003. Cultural conflict and merger failure: An experimental approach. Management Science 49:400-15.

Zingales, L. 2015. Presidential address: Does finance benefit society? Journal of Finance 70:1327-63. 